\title{
Efficacy of Modified Shortening of Levator Palpebrae Superioris Muscle on Patients with Ptosis
}

\author{
MEI LI*AND L. LI \\ Department of Ophthalmology, Dongyang People's Hospital, Jinhua 322100, China
}

Li et al.: Modified Shortening of Levator Palpebrae Superioris Muscle on Patients with Ptosis

\begin{abstract}
To explore the efficacy of modified shortening of levator palpebrae superioris muscle on patients with ptosis. A total of 78 patients with mild or moderate ptosis admitted to our hospital were enrolled and assigned to a control group and an observation group. Patients in the control group were treated with frontalis muscle suspension and those in the observation group were treated with modified shortening of levator palpebrae superioris muscle and the efficacy on ptosis of patients in the two groups was compared. The effective correction rate of the observation group was significantly higher than that of the control group $(92.59 \% \mathrm{vs} .78 .72 \%)$ and at $1^{\text {st }}$ and $7^{\text {th }} \mathrm{d}$ after operation, compared with the control group, the observation group experienced significantly more blinking times and significantly less eyelid closure insufficiency. After operation, the two groups suffered from complications including interbrow hematoma, symblepharon, eyelid entropion, ectropion or angulation, poor upper eyelid radian, exposure keratitis and the incidence of complications in the observation group was not significantly different from that in the control group. In addition, during the follow-up period, the upper eyelid retraction of the observation group was significantly less than that of the control group (all $\mathbf{p}<0.05$ ). The modified shortening of levator palpebrae superioris muscle can provide reliable efficacy for patients with ptosis and it results in less complications and smaller upper eyelid retraction.
\end{abstract}

Key words: Modified shortening of levator palpebrae superioris muscle, ptosis, clinical efficacy, eyelid closure, upper eyelid retraction

Ptosis is one of the common diseases in the ophthalmology and plastic surgery. Partial or complete ptosis may give rise to reversible vision loss, which not only seriously compromises the facial appearance, but also endangers the physical and mental health of patients $^{[1]}$. With complex causes of formation, ptosis can be congenital or secondary ${ }^{[2]}$, and congenital ptosis may impair the development of cervical spine of children $^{[3]}$. Ptosis is related to the defect of dominant nerves of levator palpebrae superioris muscle and hypoplasia of smooth muscle function and acquired aponeurotic ptosis caused by stretching or splitting of levator palpebrae superioris aponeurosis is also the most common cause of ptosis ${ }^{[4]}$. The severity of ptosis is a crucial reference index for selecting an appropriate surgical method ${ }^{[5]}$, and it is usually measured based on the Margin Reflex Distance 1 (MRD 1) and the range of the upper eyelid margin covering the cornea. MRD is the international common evaluation index for ptosis at present ${ }^{[6]}$. MRD of an examiner is the distance from the center of the light reflex to the margin of the upper eyelid of the examiner when his/her frontalis was pressed by one thumb along the long axis of his/

*Address for correspondence

E-mail: meilimey1985@126.com her eyebrow and one light source was placed in front of his/her eyes and a normal MRD is $4-5 \mathrm{~mm}$. If the muscle strength of the examiner is poor, the central light reflex of his/her cornea cannot be exposed when his/her eyes are opened. At this time, the doctor can lift the eyelid margin of the examiner with fingers and the lifting distance is recorded as a negative value, which is the MRD1 of the eye. A MRD1 smaller than 0 indicates severe ptosis ${ }^{[7]}$. The range of the upper eyelid margin covering the cornea is based on the degree of upper eyelid margin covering the upper edge of cornea after the effects of frontalis muscle were ruled out. A range of not more than $4 \mathrm{~mm}$ indicates mild ptosis, a range of not more than $6 \mathrm{~mm}$ indicates moderate ptosis and a range larger than $6 \mathrm{~mm}$ and covering the center of the pupil indicates severe ptosis ${ }^{[8]}$.

Ptosis with different severities was treated with different methods like mild ptosis can be treated by non-surgical methods but moderate and severe ptosis must be treated by surgical methods which is mainly treated by ameliorating clinical symptoms of the patients through surgical methods based on frontal muscle strength, levator palpebrae superioris muscle shortening and 
levator palpebrae superioris muscle strength enhancing. Different surgical methods have different advantages and disadvantages ${ }^{[9]}$. Among all surgical methods for correcting ptosis, correction based on levator palpebrae superioris muscle is more in line with the physiological structure of eyelids ${ }^{[10]}$, which provides more significant postoperative effect, causes less trauma and contributes to shorter operation time and postoperative recovery time, so it is almost suitable for all mild and moderate ptosis $^{[11]}$. The main surgical methods based on levator palpebrae superioris muscle include folding aponeurosis of levator palpebrae superioris muscle and shortening of levator palpebrae superioris muscle, which can increase the initial muscle length within a certain range, thus enhancing muscle strength. The two surgical methods are effective in correcting ptosis, but they still have shortcomings. Folding aponeurosis of levator palpebrae superioris muscle brings about a relatively high recurrence rate and shortening of levator palpebrae superioris muscle brings a consequence that the probability of using levator palpebrae superioris muscle is terribly small in reoperation if it overcorrects the patient ${ }^{[12]}$.

Therefore, this study adopted a modified shortening of levator palpebrae superioris muscle to treat patients with mild or moderate ptosis and followed them up to observe its clinical efficacy and postoperative complications including eyelid closure and retraction and thus evaluated the modified method.

\section{MATERIALS AND METHODS}

\section{Research objects:}

A total of 78 patients with mild or moderate ptosis admitted to our hospital from August 2018 to January 2019 were enrolled and assigned to two groups using the random number table method. The observation group ( $\mathrm{n}=42,54$ eyes) were treated with modified shortening of levator palpebrae superioris muscle, including 22 males and 20 females between 18 and $35 \mathrm{y}$ old with an average age of $(27.10 \pm 5.49)$ y while the control group $(\mathrm{n}=36,47$ eyes) were treated with frontalis muscle suspension, including 20 males and 16 females between 17 and $36 \mathrm{y}$ old with an average age of $(26.87 \pm 5.12) \mathrm{y}$. After admission, all patients were examined for fundus, frontalis muscle strength, levator palpebrae muscle strength, extraocular muscle function and preoperative vision to rule out those who had other eye diseases and all enrolled patients had not received any ocular surgery and the positions of their upper eyelid margins were not significantly different before surgery.
Exclusion criteria of the patients: Patients with severe ptosis who need non-cosmetic surgery, patients with ptosis caused by nervous system diseases, patients who had received botulinum toxin A injection within one y patients who underwent reoperation and those with both ptosis and strabismus. All the patients had no contraindications for shortening of levator palpebrae superioris muscle and they signed informed consent forms.

\section{Methods:}

\section{Modified shortening of levator palpebrae superioris}

muscle: The patient was disinfected and draped conventionally in a supine position, and then locally anesthetized through infiltration anesthesia by $2 \%$ lidocaine hydrochloride and $0.1 \%$ epinephrine mixed at $200000: 1$. The skin and subcutaneous tissues were cut open layer by layer along the line of surgical incision marking distance to sharply dissect the orbicularis oculi muscle and subcutaneous tissues and the orbicularis oculi muscle at the front of the tarsus was cut off to fully explore the attachment of the levator palpebrae superioris aponeurosis, pull down the tarsus and separate the posterior wall of the orbital septum. The bilateral retaining ligaments were released and the medial and lateral palpebral ligaments can be cut off if necessary. Subsequently, the patient was instructed to open his/her eyes to observe the muscle strength of his/her upper eyelid muscle. A tarsal plate was employed and the entire layer of the plate and palpebral conjunctiva was cut off transversely along the junction of levator palpebrae superioris aponeurosis and the plate and then plate was removed. Afterwards, the part between conjunctiva and aponeurosis was locally anesthetized through infiltration anesthesia, and the levator palpebrae superioris muscle was removed. The palpebral conjunctiva was cut off if necessary and the palpebral conjunctiva and tarsal plate incision was intermittently sutured using silk thread. A part of orbital fat was cut off appropriately and the levator palpebrae superioris muscle was pulled down to fix it at the upper $1 / 3^{\text {rd }}$ of the tarsal plate. Finally, according to the observed radian and height of palpebral margin, excess levator palpebrae superioris muscle was cut off after appropriate adjustment, and the skin was sutured through the tarsal according to the doubling eyelid operation.

\section{Frontalis muscle suspension:}

The designed surgical incision site of the patient was disinfected and draped conventionally in a supine position and then locally anesthetized. The skin and 
subcutaneous tissues were cut open along the line of surgical incision marking distance to sharply dissect the orbicularis oculi muscle with scissors and orbicularis oculi muscle with a width of about 2-3 $\mathrm{mm}$ at the anterior part of the tarsus was cut off to fully expose the tarsus and remove excess fat. The orbital septum was dissected along the tarsus and cut open transversely to expose the levator palpebrae superioris muscle. The levator palpebrae superioris muscle was cut open along the two sides of the muscle and injected with $2 \%$ lidocaine hydrochloride and $0.1 \%$ epinephrine hydrochloride under the fornical conjunctiva and palpebral conjunctiva. The palpebral conjunctiva and levator palpebrae superioris muscle were dissected sharply with scissors. The levator palpebrae superioris muscle can be pulled out loosely by cutting off the bilateral retaining ligaments and medial and lateral palpebral ligaments with curved scissors. The marked area of the frontal muscle flap was anesthetized through infiltration anesthesia and the skin was cut open under the edge of eyebrow along the orbicularis oculi muscle to bluntly dissect the skin, subcutaneous tissues and frontal muscle. Subsequently, the attachment of orbital septum was cut open along the orbital margin with a small bending forcep through an incision of the upper orbital septum of tarsus and the incision size should be suitable to pass through the levator palpebrae superioris muscle flap. The levator palpebrae superioris muscle was pulled from the orbital septum incision to the eyebrow incision and sutured with the frontal muscle through mattress suture. Afterwards, the immediate postoperative effect was evaluated and the suture was adjusted accordingly.

After the operation, the incision was cleaned, applied with erythromycin ointment, gently covered with a suitable gauze (mainly for cover), without pressing too tightly. Ice can be applied intermittently on the incision, about $15 \mathrm{~min}$ each time, within $24 \mathrm{~h}$ after operation. On the next day, the patient was encouraged to open his/her eyes more, look up slightly and keep his/her head high. On the 2nd $\mathrm{d}$ after operation, the patient was reexamined and his/her drugs were replaced and on the $7^{\text {th }} \mathrm{d}$ after operation, his/ her stitches were removed. Each patient was followed up at one and three months after the operation.

\section{Outcome measures:}

The clinical efficacy on the two groups were evaluated 1 mo after the stitches were removed, and the tear Break Up Time (BUT), Schirmer Test (SIT) level and corneal Fluorescein stain test (FL) level of the two groups were detected before surgery and at $7 \mathrm{~d}, 1 \mathrm{mo}$ and 3 mo after operation. If the BUT was less than $10 \mathrm{~s}$, the tear film was judged as instable. If the SIT observation time was $5 \mathrm{~min}$ and the wet length of the filter paper was shorter than $5 \mathrm{~mm}$, the secretion can be judged as low. During FL, the corneal coloration around the four quadrants was evaluated, including no coloration (0), scattered punctiform coloration (1), slightly dense coloration (2) and dense coloration (3), with a total score of 12 points. The incidence of complications between the two groups was compared, and both groups were followed up for 3 mo to evaluate the patients satisfaction with the operation. In addition, upper eyelid retraction of the two groups at 6 mo, 9 mo and $1 \mathrm{y}$ after operation was measured and compared between the two groups.

\section{Statistical analysis:}

Data in this study were analyzed using Statistical Package for the Social Sciences 22.0. Experimental data were expressed as the mean \pm standard deviation from at least three independent experiments, and compared between groups using the $t$ test. Enumeration data were expressed as \%, and analyzed using the chisquare $\left(\chi^{2}\right)$ test. The data were visualized into required figures using GraphPad Prism 5.

\section{RESULTS AND DISCUSSION}

The total effective correction rate of the observation group (group treated with the modified shortening of levator palpebrae superioris muscle) was significantly higher than that of the control group (group treated with frontalis muscle suspension) $(\mathrm{p}<0.05)$. We compared the blinking times and eyelid closure between the two groups at $1^{\text {st }}$ and $7^{\text {th }} \mathrm{d}$ after operation separately, finding that the observation group experienced more blinking times and less eyelid closure insufficiency than the control group (both $\mathrm{p}<0.05$ ) (Table 1 and fig. 1).

TABLE 1: COMPARISON OF CLINICAL EFFICACY BETWEEN THE TWO GROUPS

\begin{tabular}{|c|c|c|c|c|c|c|}
\hline & Number of eyes & Overcorrected & Undercorrected & Fairly corrected & Well corrected & $\begin{array}{l}\text { Total effective } \\
\text { correction rate }\end{array}$ \\
\hline $\begin{array}{l}\text { The observation } \\
\text { group }\end{array}$ & 54 & $1(1.85)$ & $3(5.56)$ & $12(22.22)$ & $38(70.37)$ & 50 (92.59) \\
\hline $\begin{array}{l}\text { The control } \\
\text { group }\end{array}$ & 47 & $4(8.51)$ & $6(12.77)$ & $10(21.28)$ & 27 (57.44) & 37 (78.72) \\
\hline$\chi^{2 / t}$ & - & & & & & 4.048 \\
\hline p-value & - & & & & & 0.044 \\
\hline
\end{tabular}


A

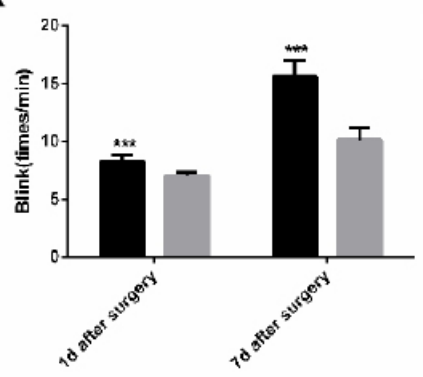

B

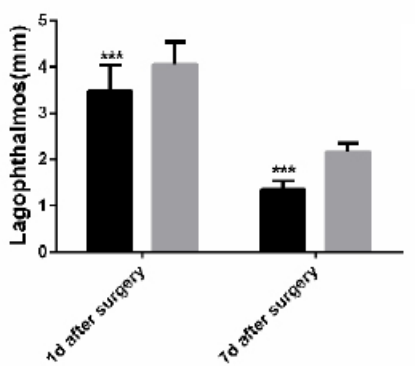

Fig. 1: Comparison of blinking times and eyelid closure after operation between the two groups; ( $\square$ ): Observation group, ( $\square$ ): Control group

There was no significant difference between the two groups in BUT, SIT and FL levels before operation and at $7 \mathrm{~d}, 1^{\text {st }}$ and $3^{\text {rd }}$ mo after operation (all p>0.05), but at $7 \mathrm{~d}$ and 1 mo after operation, both groups showed significantly increased FL level $(\mathrm{p}<0.05)$ (Table 2$)$. After operation, the two groups suffered from complications including interbrow hematoma, symblepharon, eyelid entropion, ectropion or angulation, poor upper eyelid radian, exposure keratitis and the incidence of complications in the observation group was not significantly different from that in the control group ( $7.40 \%$ vs. $14.9 \%, \mathrm{p}>0.05$ ) (Table 3 ). The upper eyelid retraction of the two groups at $6 \mathrm{mo}, 9 \mathrm{mo}$ and $12 \mathrm{mo}$ after operation was measured and it was found that the upper eyelid retraction of the observation group was significantly less than that of the control group at the same time point $(\mathrm{p}<0.0001)$ (Table 4$)$.

TABLE 2: COMPARISON OF BUT, SIT, AND FL LEVELS BETWEEN THE TWO GROUPS

\begin{tabular}{|c|c|c|c|c|c|c|}
\hline & & Number of eyes & $\begin{array}{c}\text { Before } \\
\text { operation }\end{array}$ & $\begin{array}{c}\text { At seven } \mathrm{d} \text { after } \\
\text { operation }\end{array}$ & $\begin{array}{l}\text { At one mo after } \\
\text { operation }\end{array}$ & $\begin{array}{l}\text { At three mo } \\
\text { after operation }\end{array}$ \\
\hline \multirow[t]{4}{*}{ BUT (s) } & $\begin{array}{c}\text { The observation } \\
\text { group }\end{array}$ & 54 & $16.58 \pm 4.06$ & $15.21 \pm 3.51$ & $15.63 \pm 3.98$ & $16.01 \pm 5.76$ \\
\hline & $\begin{array}{l}\text { The control } \\
\text { group }\end{array}$ & 47 & $16.63 \pm 4.12$ & $16.78 \pm 4.21$ & $16.51 \pm 3.75$ & $16.34 \pm 5.23$ \\
\hline & $\chi^{2 / t}$ & - & 0.0613 & 2.0436 & 1.1385 & 0.2997 \\
\hline & p-value & - & 0.9512 & 0.0436 & 0.2576 & 0.7651 \\
\hline \multirow[t]{4}{*}{ SIT (mm/5 min) } & $\begin{array}{c}\text { The observation } \\
\text { group }\end{array}$ & 54 & $11.21 \pm 3.68$ & $11.30 \pm 3.71$ & $11.21 \pm 3.94$ & $11.42 \pm 3.20$ \\
\hline & $\begin{array}{l}\text { The control } \\
\text { group }\end{array}$ & 47 & $11.28 \pm 3.74$ & $11.32 \pm 3.52$ & $11.25 \pm 3.81$ & $11.37 \pm 3.39$ \\
\hline & $\chi^{2} / \mathrm{t}$ & - & 0.0946 & 0.0277 & 0.0517 & 0.0762 \\
\hline & p-value & - & 0.9248 & 0.978 & 0.9589 & 0.9394 \\
\hline \multirow[t]{4}{*}{$\mathrm{FL}(\min )$} & $\begin{array}{c}\text { The observation } \\
\text { group }\end{array}$ & 54 & $0.53 \pm 0.16$ & $2.17 \pm 0.61^{*}$ & $1.34 \pm 0.55^{*}$ & $0.56 \pm 0.17$ \\
\hline & $\begin{array}{l}\text { The control } \\
\text { group }\end{array}$ & 47 & $0.52 \pm 0.15$ & $2.15 \pm 0.63^{*}$ & $1.29 \pm 0.58^{*}$ & $0.54 \pm 0.11$ \\
\hline & $\chi^{2 / t}$ & - & 0.3225 & 0.1619 & 0.4443 & 0.6903 \\
\hline & p-value & - & 0.7477 & 0.8717 & 0.6578 & 0.4916 \\
\hline
\end{tabular}

Note: * indicates $p<0.05$ vs. the situation before operation 
TABLE 3: COMPARISON OF INCIDENCE OF COMPLICATIONS BETWEEN THE TWO GROUPS

\begin{tabular}{|c|c|c|c|c|c|c|c|}
\hline & $\begin{array}{c}\text { Number of } \\
\text { eyes }\end{array}$ & $\begin{array}{l}\text { Interbrow } \\
\text { hematoma }\end{array}$ & Symblepharon & $\begin{array}{c}\text { eyelid } \\
\text { entropion, } \\
\text { ectropion, or } \\
\text { angulation }\end{array}$ & $\begin{array}{l}\text { Poor upper } \\
\text { eyelid radian }\end{array}$ & $\begin{array}{c}\text { Exposure } \\
\text { keratitis }\end{array}$ & $\begin{array}{c}\text { Incidence of } \\
\text { complications } \\
\text { (\%) }\end{array}$ \\
\hline $\begin{array}{l}\text { The } \\
\text { observation } \\
\text { group }\end{array}$ & 54 & $1(1.85)$ & $1(1.85)$ & $1(1.85)$ & $1(1.85)$ & $0(0)$ & $4(7.40)$ \\
\hline $\begin{array}{l}\text { The control } \\
\text { group }\end{array}$ & 47 & $2(4.25)$ & $1(2.13)$ & $1(2.13)$ & $2(4.25)$ & $1(2.13)$ & $7(14.9)$ \\
\hline$\chi^{2 / t}$ & - & & & & & & 1.451 \\
\hline$p$ value & - & & & & & & 0.2283 \\
\hline
\end{tabular}

TABLE 4: UPPER EYELID RETRACTION OF THE TWO GROUPS AFTER OPERATION

\begin{tabular}{lcccc}
\hline & Number of eyes & $\begin{array}{c}\text { At six mo after } \\
\text { operation }\end{array}$ & $\begin{array}{c}\text { At nine mo after } \\
\text { operation }\end{array}$ & $\begin{array}{c}\text { At twelve mo after } \\
\text { operation }\end{array}$ \\
\hline The observation group & 54 & $0.25 \pm 0.07$ & $0.30 \pm 0.09$ & $0.32 \pm 0.08$ \\
The control group & 47 & $0.34 \pm 0.09$ & $0.41 \pm 0.10$ & $0.53 \pm 0.15$ \\
$\chi^{2} / \mathrm{t}$ & - & 5.645 & 8.329 & 8.935 \\
$\mathrm{p}$ value & - & $<0.0001$ & $<0.0001$ & $<0.0001$ \\
\hline
\end{tabular}

Ptosis is a common eye deformity and congenital ptosis is mostly caused by hypoplasia of levator palpebrae superioris muscle and abnormal development and dysfunction of dominant oculomotor nerves of levator palpebrae superioris muscle. Some patients with congenital ptosis have a family history of the disease $^{[13]}$. The function of levator palpebrae superioris muscle is to lift and control the upper eyelid muscle. If the levator palpebrae superioris muscle is congenital hypoplasia or is affected by traumatic, neurogenic, or myogenic factors, it is very likely that the levator palpebrae superioris muscle will undergo functional changes, thus causing ptosis. Raising the upper eyelid and strengthening the muscle strength of upper eyelid are essential for the correction of ptosis ${ }^{[14]}$. Frontalis muscle suspension and shortening of levator palpebrae superioris muscle are both common surgical methods for severe ptosis. Direct frontalis muscle suspension is to ameliorate the symptoms of ptosis by lifting the upper eyelid with the strength of frontalis muscle as a supplementary strengthen or replaced strength and indirect frontalis muscle suspension is to connect the frontalis muscle and tarsus through other materials while shortening of levator palpebrae superioris muscle is an operation method for shortening the levator palpebrae superioris muscle ${ }^{[15-17]}$. Frontalis muscle suspension can lift the upper eyelid with the aid of frontalis muscle to increase the power of lifting eyelid and achieve good surgical results. However, due to its non-compliance with normal physiological structure the operation is prone to massive hemorrhage, complicated to operate, easy to damage the domain nerves and blood vessels and it also results in many postoperative complications, so it is difficult to meet the patients surgical expectations ${ }^{[18,19]}$. Shortening of levator palpebrae superioris muscle can enhance the muscle strength of levator palpebrae superioris muscle, maintain the original walking and movement direction of muscle and conforms to the physiological function of human body, so it facilitates postoperative recovery and aesthetic appearance and can effectively improve the therapeutic effect ${ }^{[20,21]}$.

In this study, we adopted frontalis muscle suspension and modified shortening of levator palpebrae superioris muscle to treat patients with ptosis respectively, to compare the clinical efficacy of the two methods. The results of the study were as mentioned below.

The effective correction rate of patients treated with modified shortening of levator palpebrae superioris muscle was significantly higher than that of patients treated with frontalis muscle suspension and except for the difference in BUT between the two groups at $7 \mathrm{~d}$ after operation, there was no significant difference between them in BUT, SIT and FL levels at other time points. In addition, about $7 \mathrm{~d}$ after frontalis muscle suspension, the upper eyelids of the patients were swollen due to the frontalis muscle flap, resulting in different degrees of upper eyelid height reduction and relative reduction of corneal exposure area. As a result, the tear break-up time of the patients was relatively long and the patient suffered from punctate or flaky epithelial infiltration 
of cornea because they cannot blink and close eyes to supplement the unstable tear film and the cornea is exposed to the air for a long time ${ }^{[22]}$, resulting in an increase in FL score. As the time went on, patients showed subsiding of frontalis muscle swelling, gradual recovery of upper eyelid height and gradual reduction of cornea exposure area and the cornea exposure area was equivalent to that of the patients who underwent modified shortening of levator palpebrae superioris muscle $^{[23]}$, so there was no difference between the two groups in BUT at the later stage.

At $1^{\text {st }}$ and $7 \mathrm{~d}$ after the operation, compared with the control group, the observation group treated with modified shortening of levator palpebrae superioris muscle experienced significantly increased blinking times and significantly less eyelid closure insufficiency and after operation, both groups suffered from complications including interbrow hematoma, symblepharon ${ }^{[24]}$, eyelid entropion, ectropion or angulation, poor upper eyelid radian and exposure keratitis $^{[25]}$, and the incidence of complications in the observation group was not significantly different from that in the control group, indicating that the safety of the two surgical methods is equivalent. Furthermore, during the follow-up period after operation, the upper eyelid retraction of the observation group was significantly less than that of the control group, implying that modified shortening of levator palpebrae superioris muscle has better long-term effect, can effectively prevent upper eyelid retraction after operation and ensure the surgical effect.

To sum up, the modified shortening of levator palpebrae superioris muscle for patients with mild or moderate ptosis has the advantages of simple operation, small trauma, strong controllability, and lasting and reliable effect, which can provide ideal correction effect, with guaranteed safety, so it is worthy of recommendation and application.

\section{Conflict of interests:}

The authors declared no conflicts of interest.

\section{REFERENCES}

1. Ho SF, Morawski A, Sampath R, Burns J. Modified visual field test for ptosis surgery (Leicester Peripheral Field Test). Eye 2011;25(3):365-9.

2. Clauser L, Tieghi R, Galiè M. Palpebral ptosis: clinical classification, differential diagnosis, and surgical guidelines: An overview. J Craniofac Surg 2006;17(2):246-54.

3. Shetty A, Craig PR, Chitgopkar SD. An observation of massive lumbar disc prolapse. J Spine Surg 2018;4(3):583-7.
4. Lim JM, Hou JH, Singa RM, Aakalu VK, Setabutr P. Relative incidence of blepharoptosis subtypes in an oculoplastics practice at a tertiary care center. Orbit 2013;32(4):231-4.

5. Byard SD, Sood V, Jones CA. Long-term refractive changes in children following ptosis surgery: A case series and a review of the literature. Int Ophthalmol 2014;34(6):1303-7.

6. Nemet AY. Accuracy of marginal reflex distance measurements in eyelid surgery. J Craniofac Surg 2015;26(7):e569-71.

7. Patel RM, Aakalu VK, Setabutr P, Putterman AM. Efficacy of Muller's muscle and conjunctiva resection with or without tarsectomy for the treatment of severe involutional blepharoptosis. Ophthal Plast Reconstr Surg 2017;33(4):2738.

8. Ng DS, Chan E, Ko ST. Minimal incision posterior approach levator plication for aponeurotic ptosis. Eye 2015;29(4):48391.

9. Innocenti A, Mori F, Melita D, Dreassi E, Ciancio F, Innocenti M. Evaluation of long-term outcomes of correction of severe blepharoptosis with advancement of external levator muscle complex: descriptive statistical analysis of the results. In Vivo 2017;31(1):111-5.

10. Tu Y, Gao F. Dexmedetomidine-based monitored conscious sedation combined local anesthesia for levator resection in a 10-year-old child with Marcus Gunn jaw-winking synkinesis: A case report. Medicine 2017;96(51): e9369.

11. Mawatari Y, Fukushima M, Kawaji T. Changes in sunken eyes combined with blepharoptosis after levator resection. Plast Reconstr Surg Glob Open 2017;5(12):e1616.

12. Liu CY, Chhadva P, Setabutr P. Blepharoptosis repair. Curr Opin Otolaryngol Head Neck Surg 2018;26(4):221-6.

13. Couch SM. Correction of eyelid crease asymmetry and ptosis. Facial Plast Surg Clin North Am 2016;24(2):153-62.

14. Miao X, Wang T, Zhou X, Song W, Wang J. A new surgical technique used for correction of congenital blepharoptosis. Aesthetic Plast Surg 2020;44(3):810-9.

15. Majumder RK, Haque T. A Case of Single Atrium, Mitral Valve Prolapse Spontaneously-Closed Inlet VSD with Polydactyly. Mymensingh Med J 2018;27(4):894-7.

16. Chen W, Liu Z, Tian Q, Niu H, Liu F, Wang X, et al. Levator resection with suspensory ligament of the superior fornix suspension for correction of pediatric congenital ptosis with poor levator function. Eye 2016;30(11):1490-5.

17. Kokubo K, Katori N, Hayashi K, Kasai K, Kamisasanuki $\mathrm{T}$, Sueoka K, et al. Frontalis suspension with an expanded polytetrafluoroethylene sheet for congenital ptosis repair. J Plast Reconstr Aesthet Surg 2016;69(5):673-8.

18. Chung HW, Seah LL. Cosmetic and functional outcomes of frontalis suspension surgery using autologous fascia lata or silicone rods in pediatric congenital ptosis. Clin Ophthalmol 2016;10:1779-83.

19. Marenco M, Macchi I, Macchi I, Galassi E, Massaro-Giordano M, Lambiase A. Clinical presentation and management of congenital ptosis. Clin Ophthalmol 2017;11:453-63.

20. Wang PH. Mid-urethral sling in the management of women with stress urinary incontinence after pelvic organ prolapse treatment. Taiwan J Obstet Gynecol 2018;57(6):777-8.

21. Lai HT, Weng SF, Chang CH, Huang SH, Lee SS, Chang KP, et al. Analysis of levator function and ptosis severity in involutional blepharoptosis. Annal Plastic Surg 2017;78(3):S58-60.

22. Ho YF, Wu SY, Tsai YJ. Factors associated with surgical outcomes in congenital ptosis: A 10-year study of 319 cases. Am J Ophthalmol 2017;175:173-82. 
23. Wang T, Li X, Wang X, Wang Q, Li W, Zhou L, et al. Evaluation of moderate and severe blepharoptosis correction using the interdigitated part of the frontalis muscle and orbicularis oculi muscle suspension technique: A cohort study of 235 cases. J Plast Reconstr Aesthet Surg 2017;70(5):692-8.

24. Li J, Dong C, Liu X, He W. Treatment of children with congenital severe blepharoptosis by frontalis aponeurosis flap advancement under general anesthesia in a single incision. $\mathrm{J}$ Craniofac Surg 2017;28(6):1495-7.
25. Saonanon P, Sithanon S. External levator advancement versus Müller muscle-conjunctival resection for aponeurotic blepharoptosis: A randomized clinical trial. Plast Reconstr Surg 2018;141(2):213e-9e.

This is an open access article distributed under the terms of the Creative Commons Attribution-NonCommercial-ShareAlike 3.0 License, which allows others to remix, tweak, and build upon the work non-commercially, as long as the author is credited and the new creations are licensed under the identical terms

This article was originally published in a special issue, "Novel Therapeutic Approaches in Biomedicine and Pharmaceutical

Sciences" Indian J Pharm Sci 2021:83(6) Spl Issue "191-197" 